\title{
Analisa dan Perancangan Aplikasi Penjualan Tanaman Hias Berbasis Online Sebagai Media Promosi Bagi Salman KS Flowers
}

\author{
Arman $^{1}$, Elizamiharti ${ }^{2}$ Muhammad Saf'an ${ }^{3}$ \\ ${ }^{1,2,3}$ Sistem Informasi STMIK Indonesia Padang \\ Jln. Khatib sulaiman Dalam No. 1 Padang, (0751) 7056199 \\ Email: ${ }^{1}$ arman@stmikindonesia.ac.id, ${ }^{2}$ elizamiharti2@gmail.com, \\ ${ }^{3}$ muhammadsafan61@gmail.com
}

\begin{abstract}
Abstrak
CV. Salman KS Flowers merupakan salah satu Usaha Kecil Menengah (UKM) yang bergerak dalam penjualan tanaman hias yang dapat memberikan kontribusi yang sangat signifikan dalam memacu pertumbuhan perekonomian di Sumatera barat khususnya kota Padang. Hal itu disebabkan karena semua UKM tersebut banyak menyerap tenaga kerja, sehingga dapat menurunkan tingkat penganguran. Akan tetapi UKM yang ada di kota Padang masih menghadapi banyak masalah antara lain masalah penjualan, pemasaran dan promosi selama ini masih belum menggunakan aplikasi. Berdasarkan masalah yang terjadi peneliti mencarikan sulusi dengan merancang sebuah aplikasi penjulan tanaman hias berbasis online, aplikasi ini dapat membantu $C V$. Salman KS. Flowers dalam penjulan dan pemasaran produk. Hasil dari penelitian ini merancang sebuah sistem informasi penjualan Tanaman hias berbasis online sebagai media promosi. Aplikasi ini dirancang dapat digunakan oleh pelanggan salman KS Flowers secara baik dinilai dari 10 aspek. Setelah dilakukan pengujian melalui responden hasilnya menunjukan rata-rata Skor SUS sebesar 72 dengan Grade C. untuk pengujian beta diberikan oleh responen sistem ini dinilai dengan hasilnya layak dengan nilai rata-rata 72 dan Responden terdiri dari 30 orang pengguna yaitu pelanggan salman KS Flowers. Hasil pengujian menunjukan 54 \% pengguna menilai aplikasi ini cukup layak digunakan, $30 \%$ menilai layak dan $16 \%$ menilai aplikasi ini kurang layak.
\end{abstract}

Kata kunci : Sistem Informasi, Sarana, Penjualan Tamaman Hias, Online, UML

\begin{abstract}
CV. Salman KS Flowers is one of the Small and Medium Enterprises (UKM) engaged in the sale of ornamental plants that can provide a very significant contribution in spurring economic growth in West Sumatra, especially the city of Padang. This is because all these SMEs absorb a lot of labor, which can reduce unemployment rates. However, SMEs in the city of Padang still face many problems, including sales, marketing and promotion issues, so far they are still not using the application. Based on the problems that occur, researchers find sulusi by designing an application for selling ornamental plants based online, this application can help $C V$. Salman KS. Flowers in sales and product marketing. The results of this study designed an online-based ornamental plant sales information system as a promotional medium. This application is designed to be used by customer salman KS Flowers is well assessed from 10 aspects. After testing through respondents the results showed an average score of SUS of 72 with Grade C. For beta testing given by response the system was assessed with the results feasible with an average value of 72 and the respondents consisted of 30 users, namely KS Flowers' customer. The test results showed 54\% of users rated this application as quite feasible to use, $30 \%$ rated it feasible and $16 \%$ rated this application as inappropriate.
\end{abstract}

Keywords : Information Systems, Facilities, Tamaman Ornamental Sales, Online, UML 


\section{Pendahuluan}

Indonesia merupakan salah satu Negara dengan populasi penduduk terbesar didunia. Keadaan ini tidak selalu merugikan, melainkan memberikan keuntungan besar bagi indonesia. Oleh karena itu Negara Indonesia merupakan sebuah pasar potensial bagi dunia bisnis dan perdagangan. Semua itu dapat dilihat dari banyaknya perusahaan komersial yang ada diseluruh penjuru Indonesia, bersaing untuk menguasai pangsa pasar untuk mengatur stategis bisnisnya masing-masing, salah satunya dengan menmanfaatkan TI secara obtimal untuk mendukung berbagai kegiatan[1]. Sumatera Barat adalah salah satu Provinsi di Indonesia yang terletak di pulau Sumatera dengan Padang sebagai ibu kotanya. Sesuai dengan namanya, wilayah provinsi ini menempati sepanjang pesisir barat Sumatera bagian tengah, dataran tinggi Bukit Barisan di sebelah timur, dan sejumlah pulau di lepas pantainya seperti Kepulauan Mentawai. Dari utara ke selatan, provinsi dengan wilayah seluas $42.297,30 \mathrm{~km}^{2}$ ini berbatasan dengan empat provinsi, yakni Sumatera Utara, Riau, Jambi, dan Bengkulu.

Di Sumatera Barat khusunya kota padang banyak terdapat UKM yang bergerak dalam berbagai usaha dan bisnis. Salah satunya adalah CV. Salman KS. Flowers yang terletak di jalan Baypass. $100 \mathrm{KM}$. Yang bergerak dalam usaha Penjualan tanaman hias, selama ini banyak memberikan kontribusi yang sangat signifikan dalam memacu pertumbuhan perekonomian di kota Padang. Hal itu disebabkan karena semua UKM tersebut banyak menyerap tenaga kerja, sehingga dapat menurunkan tingkat penganguran, akan tetapi CV. Salman ini juga banyak mengalami permasalah antara lain dalam penjulan. Selain itu juga pengelolaan yang kurang profosional, [2] maupun strategi promosi dan pemasaran suatu produk [3]. Tujuannya semua itu adalah agar perusahan dapat meningkatkan omsetnya. Selain itu CV. Salman belum mengimplementasikan strategi dan sistem pemasaran yang belum mendukung [4]. Sehingga CV. Salman mengalami kesulitan dalam memasarkan produk yang produksinya. Dengan adanya sarana teknologi yang dapat diakses oleh pelangan, salaha satunya dengan menggunakkan sarana teknologi seperti Website [5], Media Interaktif Berbasis Artom [6], Media sosial dan instagram [7] dan aplikasi lainnya yang dapat diakses secara online. Semua Jaringan internet dapat dimanfaatkan dan memfasilitasi setiap manusia di penjuru dunia untuk berhubungan satu sama lain tanpa dibatasi oleh ruang dan waktu. Tidak dipungkiri sekarang ini bahwa internet sudah menjadi suatu kebutuhan bagi masyarakat.

Perkembangan internet yang sekarang ini sudah banyak dimanfaatkan diberbagai kalangan antara lain, Perkantoran [8], Sekolah [9], Bisnis [10], maupun usaha yang lainnya. ECommerce memberikan peluang pasar yang sangat besar. Terutama bagi UKM yang berkeinginan untuk memasarkan produknya secara global, dan juga dapat dijadikan sebagai informasi yang memuat iklan sekaligus menampilkan produk yang dibutuhkan oleh pelangang untuk mendapatkan informasi tentang produk yang mereka hasilkan.

Berdasarkan uraian diatas CV. Salman KS Flowers salah satu UKM yang bergerak dalam penjualan tanaman hias. Permasalahan yang dihadapi selama ini adalah belum memanfaatkan teknologi (convesional) dalam penjualan, promosi tanaman hias, pengolahan data pelangnggan, pembuatan laporan transaksi, pemasaran hasil produk bagi bagi pelanggannya. Untuk pemasaran dan promosi produk masih manual, sehingga hasil penjualan tidak optimal, perusahan tidak mampu bersaing dengan perusahan sejenis dan pemasaran pun tidak luas.

Beberapa penelitian yang terdahulu yang sudah membahas tema sistem informasi penjualan adalah penelitian oleh [11] mencoba menerapkan teknologi internet untuk komunitas Petani Bunga di desa Blabak dapat maju dan berkembang lebih maju, salah satunya dengan hasil penelitiannya merancang sebuah aplikasi yang berguna untuk memasarkan hasil produksi di kalangan kelompok petani bunga dengan cara saling bertukar produk dengan sesama kelompok untuk pelangan meraka masing-masing petani. Selain itu dapat meningakatkan 
penjualan produk yang di produksi oleh perusahan tersebut. Dengan adanya aplikasi disetiap kelompok petani dapat memberikan berdampak posistif salah satu adalah meningkatkan omset setip kelompok Petani Bunga dari sebelumnya.

Penelitian yang dilakukan oleh [12] pada penelitian ini peneliti merancang sebuah aplikasi berbasi web untuk memasarkan produk secara online. Dalam bisnis produk usaha tamanan bunga dapat dipasarkan melalui suatu wadah tertentu dengan tujuan untuk memasarkan suatu produk secara sistem pemasaran online. Sistem aplikasi ini dirancang berbasis mobile. Tujuan aplikasi adalah memudahkan pelanggan dalam proses transaksi dan pemasaran barang yang dihasilkannya, selain itu juga dapat dijangkau pelanggan dengan menggunakan media aplikasi seperti FB, WA, Twiter secara langsung dimana dan kapan saja pelanggan menbutuhkannya. Pada penelitian ini aplikasi dirancanga dengan bahasa pemrograman PHP, Java dan mysql.

Selanjutnya penelitian oleh [13] merancang suatu aplikasi pemasaran secara online berbasis web dengan menggunakan fasilitas secara online. Aplikasi ini dapat menjadikan pasar pemasaran barang bertambah luas, karena sudah dapat diakses dimana saja pelanggan berada. Bertambahnya jumlah pelanggan diharapkan dapat menambah omset penjualan tanaman hias setiap waktu. Kesimpulan yang dapat diambil, dengan penerapan aplikasi e-commerce semua permasalahan yang dihadapi dapat diselesaikan dengan baik.

Penelitian lain [14] penelitian ini dilaksanakan pada Dinas Pertanian Kota Tomohon, pemerintahnya berencana ekspor bunga unggulan ke luar daerah, tentu ini membutuhkan support dalam hal promosi, sosialisasi dan informasi bagi masyarakat yang menjadi calon pelanggan di luar daerah. Agar semua rencana itu dapat direalisasikan tentu ada usaha yang harus lakukan oleh pemerintah setempat. Salah satunya adalah merancang sebuah aplikasi website untuk penjualan dan promoasi bunga secar online, yang dikelola oleh Dinas Pertanian, sebagai sarana untuk pemasaran produk bunga di Kota Tomohon.

Berdasarkan urian dari beberapa peneliti tersebut dapat disimpulkan bahwa dengan menggunakan aplikasi yang berbasis web dan menggunakan teknologi semua produk yang dihasilkan oleh UKM dapat dipasarkan secara online, lebih efisien dan efektif. Sehingaa pelanggan udah untuk melihat semua produk yang dihasilkan oleh UKM di mana saja pelangan itu berada tampa mereka harusa datang ketempat prosuksi.

\section{Metode Penelitian}

Penelitian ini berupa study kasus dengan menggunakan metode model UML, yang terdiri dari beberapa tahapan, yaitu tahapan pengumpulan data, pada tahap awal ini kegiatan yang dilakukan adalah pengumpulan data-data yang berkaitan dengan masalah tentang penelitian. Tahap berikutnya[15] adalah tahap analisa data, pada tahap ini menjelaskan mengenai sistem yang sedang berjalan saat ini, kemudian tahap berikutnya adalah tahapan perancangan sistem, dimana pada tahap perancangan sistem ini akan berkaitan perancangan sistem yang sesuai dengan kebutuhan yang digunkan pada aplikasi penjualan secara online.

\subsection{Pengumpulan Data}

\section{Jenis Data Yang Dibutuhkan}

a. Data Primer yaitu data yang didapat dari observasi maupun dari hasil wawancara secara langsung yang diperoleh dari lapangan. Data tersebut diperoleh dari CV. Salman KS Flowers, data yang terdiri dari data tanaman hias, seperti jenis tanaman hias, harga, pelanggan, transaksi.

b. Data Sekunder adalah data yang digunakan dalam penelitian secara tidak langsung, data yang diperoleh tidak dari survey maupun pengamatan tidak secara langsung, tapi data diperoleh dari sumber-sumber jurnal, buku, prosiding dan hasil penelitian sebelumnya yang berhubungan dengan pembahasan perancangan aplikasi penjualan tanaman hias berbasis online.

\section{Sumber Data}


Sumber data yang dibutuhkan dalam penelitian ini diperoleh dari CV. Salman KS. Flowers

\section{Pengumpulan Data}

Dalam pengumpulan data penelitian ini digunakan tiga cara yaitu :

a. Metode Observasi secara langsung, dimana pengumpulan data dilakukan secara langsung ke CV. Salman yang beralamat di jln. Baypas $100 \mathrm{KM}$ dan melihat permasalahan yang terjadi disana tentang data penjualan, pemasaran dan promosi.

b. Wawancara, metode ini merupakan pengumpulan data yang diperoleh dari hasil dari wawancara secara langsung, baik kepada pimpinan, karyawan dan pelanggan CV. Salman.

c. Tinjaun pustaka, metode ini dilakukan pengumpulan data dari beberapa sumber dari pustaka yang berkaitan dengan permasalahan dan yang berhubungan dengan penelitian.

\subsection{Analisa Data}

Sistem penjualan, pemasaran, promosi dan pengolahan data yang digunakan pada CV. Salman KS. Flowers yang sudah berjalan masih mengalami kendala, sistemnya masih menggunakan media telpon/HP, atau pelanggan harus datang langsung ketempat produksi. sehingga tidak semua pelanggan atau masyarakat yang mengetahui secara luas. Dengan adanya teknologi informasi dan menggunakan media internet dapat membuat peluang bagi setiap usaha atau UKM untuk menjual, memasarkan dan mempromosikan hasil prodik secara luas. Salah satunya aplikasi berbasis online. Berikut ini adalah aliran data penjualan yang dilakukan oleh CV. Salman KS. Flowers tentang penjualan tanaman hias yang sedang berjalan saat ini. Untuk lebih jelas dapat dilihat pada Gambar 1.

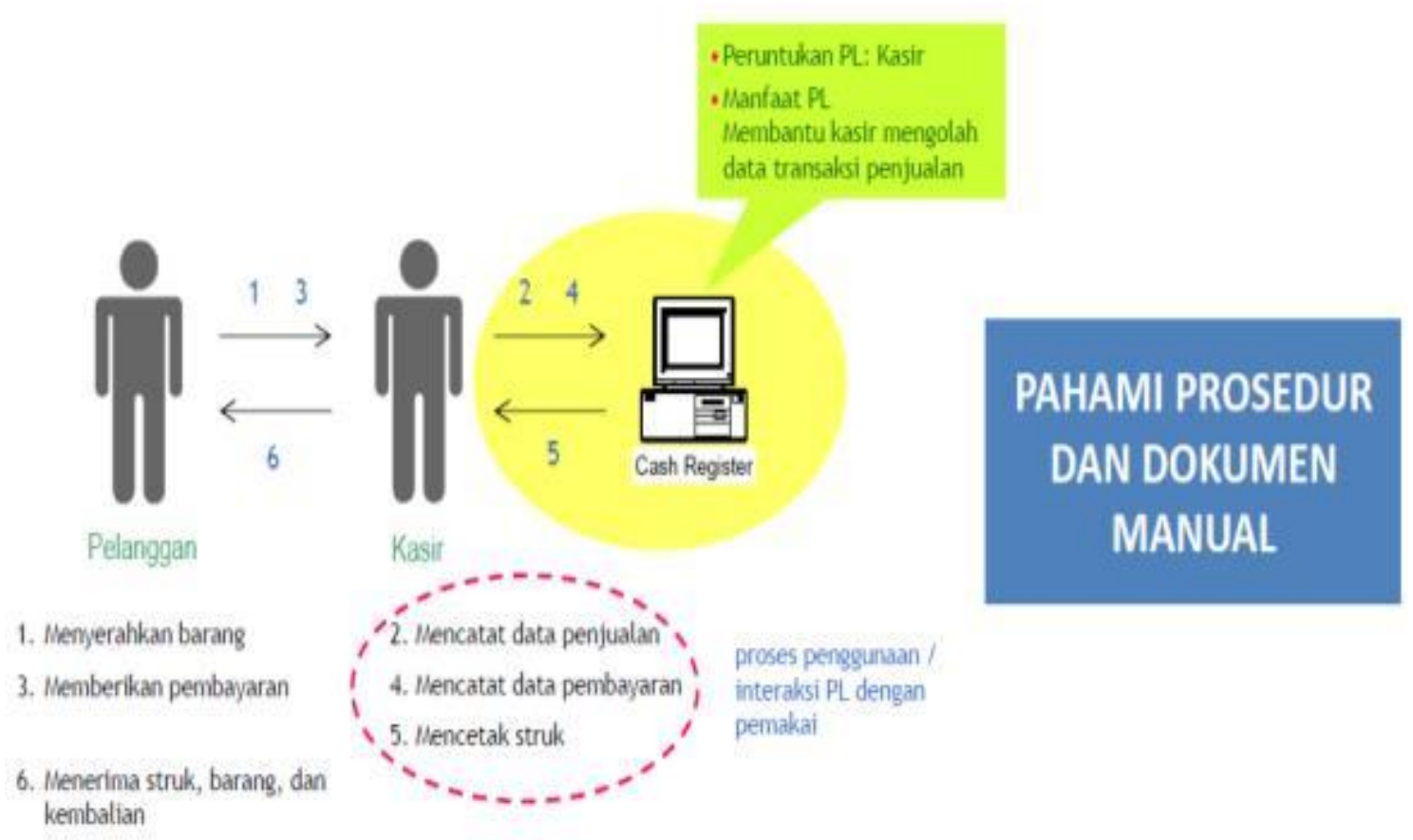

Gambar 1. Penjualan Tanaman Hias Yang Sedang Berjalan

Dengan adanya teknologi informasi dan menggunakan fasilitas internet, CV. Salman dapat lakukan penjualan, pemasaran dan mempromosikan hasil prodik secara luas dengan menggunakan aplikasi berbasis online.Beriut ini adalah aliran sistem informasi penjualan secara online. untuk lebih jelas dapat dilihat pada Gambar 2. 


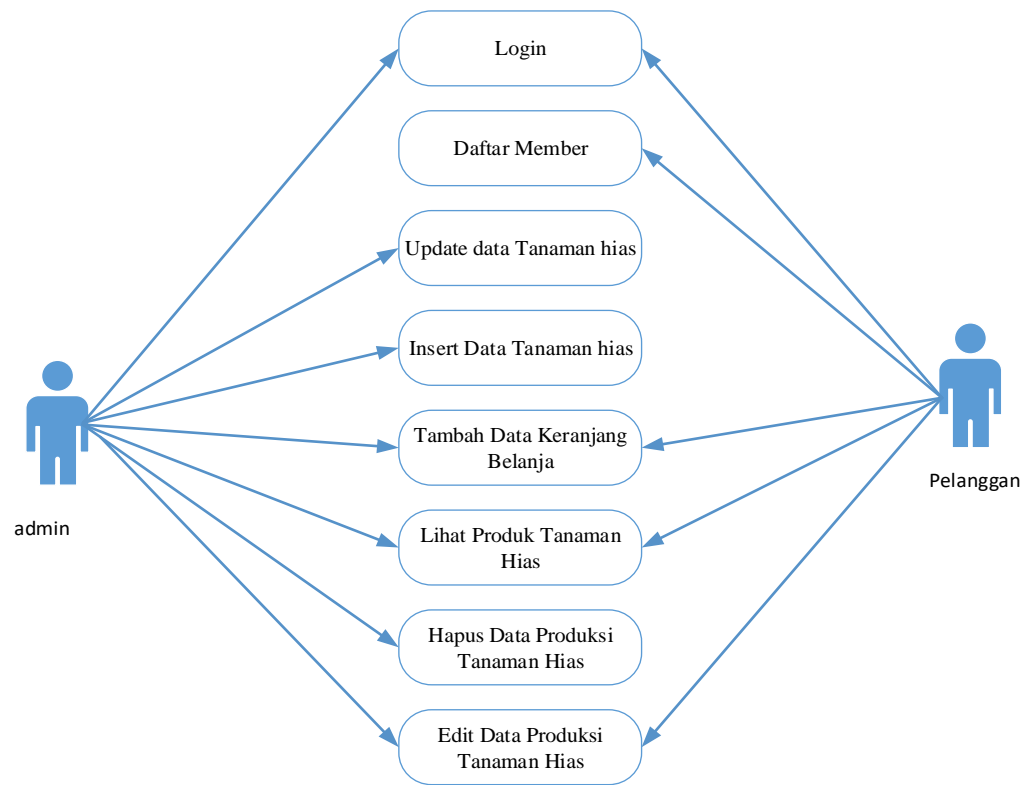

Gambar 2. Sistem Informasi Penjualan Secara Online

Berdasarkan dari gambar 1 dan 2 diatas, dapat dilihat adanya perobahan dari sistem manual ke sistem aplikasi yang berbasis web atau online dalam penjualan tanaman hias. Selain itu juga aplikais dapat digunakan sebagai media promosi bagi pelanggan Salman untuk melihat jenisjenis tanaman hias yang dijualnya, pelanggan dapat mengakses aplikasi dari mana dan kapan saja.

\subsection{Perancangan Sistem}

Perancangan sistem yang digunakan adalah dengan UML. Tahapan ini melakukan rancangan dari sistem yang akan rancang. Sesuai dengan kebutuhan sistem yang akan dirancanga, ada input, proses dan output pada Sistem Informasi penjualan tanaman hias. Perancangan sistem yang akan dibangun sesuai dengan Kebutuhan dapat memberikan salah satu persyaratan secara teknis, dan dapat mengidentifikasi informasi yang akan ditampilkan pada aplikasi berbasis web untuk dapat penyelesai masalah-masalah yang dihadapi oleh perusahan. Selain itu juga ada melakukan analisis tentang hubungan basis data yang ditampilkan dalam sistem. Dalam clase digram, Use case, Uutuk mengetahui siapa saja aktor yang terlibat dalam sistem informasi penjualan produk di Salman KS Flowers, untuk mempermudah dalam analisisnya. Untuk lebih jelasnya dapat dilihat pada Gambar 3.

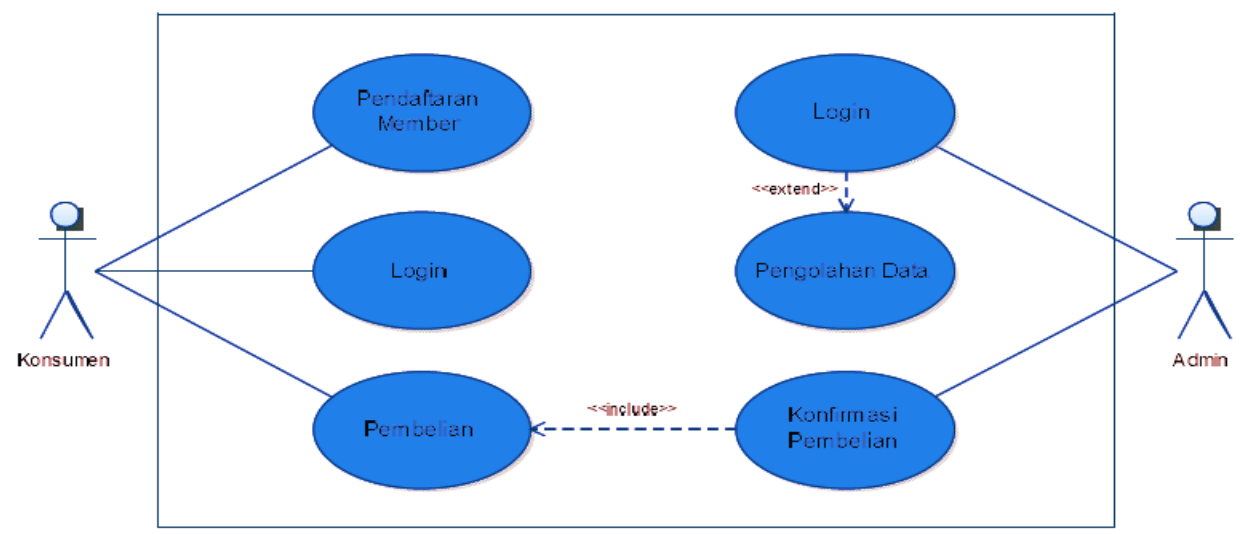

Gambar 3. Use case diagram yang diusulkan

Class Diagram menggambarkan struktur statis class di dalam sistem. Class merepresentasikan sesuatu yang ditangani oleh sistem. 


\section{Hasil Dan Pembahasan}

Hasil dari program berdasarkan rancangan dan kebutuhan sistem yang sudah dianalisis sebelumnya. Selain itu juga melakukan proses pengujian sistem yaitu melakukan uji coba tentang kesesuain dari system yang sudah dirancang seperti: (1) Kesalahan dalam penulisan kode program sama software pemrograman yang dipakai, (2) Kesalahan dalam membuat rumus untuk proses, kesalahan tampil program waktu dioperasikan oleh pengguna. Kesalahn yang tampil ini dapat mengakibatkan kepada jalannya program, dan juga dapat mengakibatkan program dapat berhenti sebelum waktu proses selesai. (3) Kesalahan diwaktu membuat logika program, kesalahan pada bagian ini sangat sulit lihat, sebab kesalahan tidak terlihat pada waktu program berjalan. Pada saat dijalankan program tampil normal dan baik, namun ouputnya salah. Pada tahap ini sistem diuji setelah sistem selesai dikerjakan, disamping itu juga memelihara aplikasi dengan tujuan untuk sistem dapat berjalan secara stabil dan berjalan dengan baik . Selain itu aplikasi yang dirancang juga menyediakan fasilitas kesalahan saat user serangan virus. Setelah dilakukan pengembangan sistem akan dilakukan analisis terkait kelayakan dengan pemberian nilai terkait 10 aspek.

Kemudahan Semua aspek tersebut dijabarkan dalam 10 pernyataan yang diberikan kepada responden, dan hasil penilaian akan dihitung dengan menggunakan skala likert dari kategori Tidak Layak hingga Sangat Layak. Dalam perancangan aplikasi ini menggunakan bahasa pemrogrman php, Dramwever, addobe dan software pendukung. Akses untuk admin sebagai pengelolah data pelanggan, transaksi, penjuan dan stock yang ada. Akses sebagai pimpinan dapat melihat berapa jumlah penjualan, jumlah traksaksi. Akses sebagai pelanggan berfungsi sebagai dapat melihat jenis tanaman, belanja, harga, jumlah stock. Pada Gambar. 4 ini merupakan tampilan awal dari menu utama dari sistem informasi penjualan tanaman Hias.

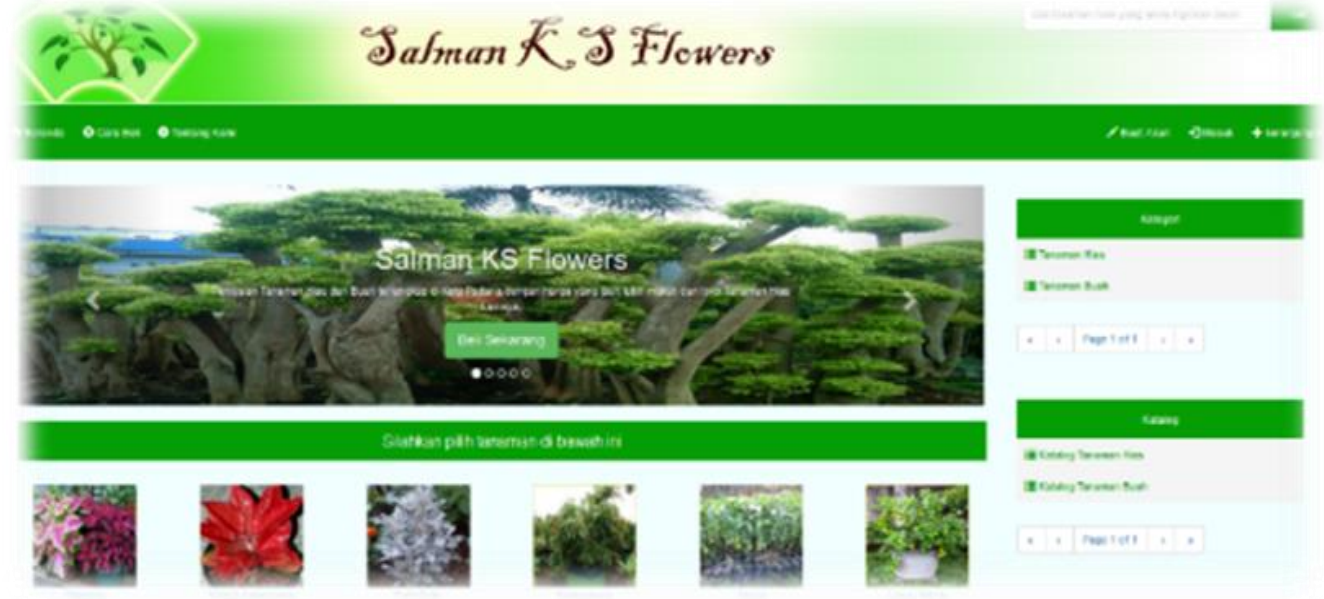

Gambar 4. Tampilan Menu utama dari Sistem

Gambar 4 menyajikan Mеnи Home Member yang pertama kali diakses oleh member aplikasi penjualan tanaman hias untuk menampilkan informasi daftar produk. Pada halaman ini member dapat melihat jenis tanaman hias yang ditawarkan. Dalam menu ini pengunjung dapat mengakses sub-sub menu lain seperti profil, kategori produk, panduan cara beli, dan halaman ini member bisa bertransaksi pemesanan tanaman hias.

Gambar 5 merupakan Halaman Home Admin melakukan login sebagai admin. Admin dapat melakukan pengentrian data, mengedit data, maupun menghapus data yang ada dalam sistem., тепи data pelanggan, тепи daftar pesanan pelanggan, тепи status pengiriman, dan mеnu laporan transaksi. Di dalam setiap halaman yang terdapat pada mеnu tersebut mempunyai fungsi masing-masing yang tentunya dibutuhkan oleh sistem penjualan tanaman hias. Untuk lebih jelas dapat dilihat pada Gambar 5. 


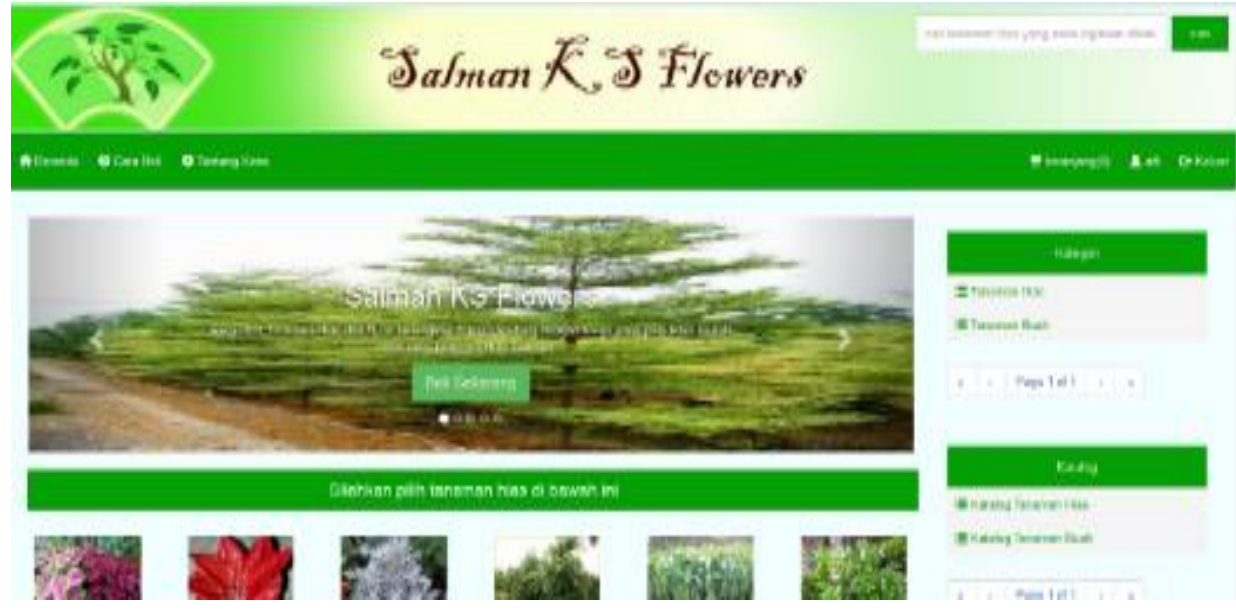

Gambar 5. Tampilan Halaman Home Member dari Sistem

Pada Gambar.6 Merupakan menu untuk menampilkan informasi tentang profile toko tanaman hias kepada pengunjung baru maupun member dapat mengetahui keberadaan lokasi tanaman hias.
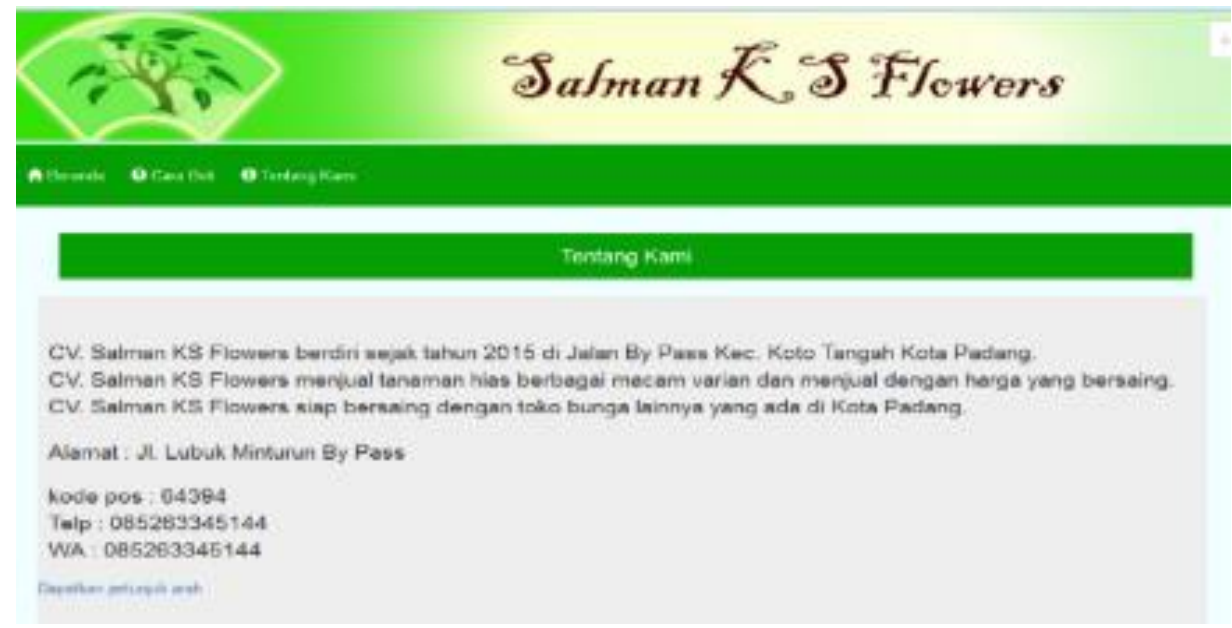

Gambar 6. Tampilan Menu Profil

Pada ini Halaman input data kategori ini berguna untuk admin untuk input data kategori tanaman hias. Untuk lebih jelas dapat dilihat pada Gambar 7.

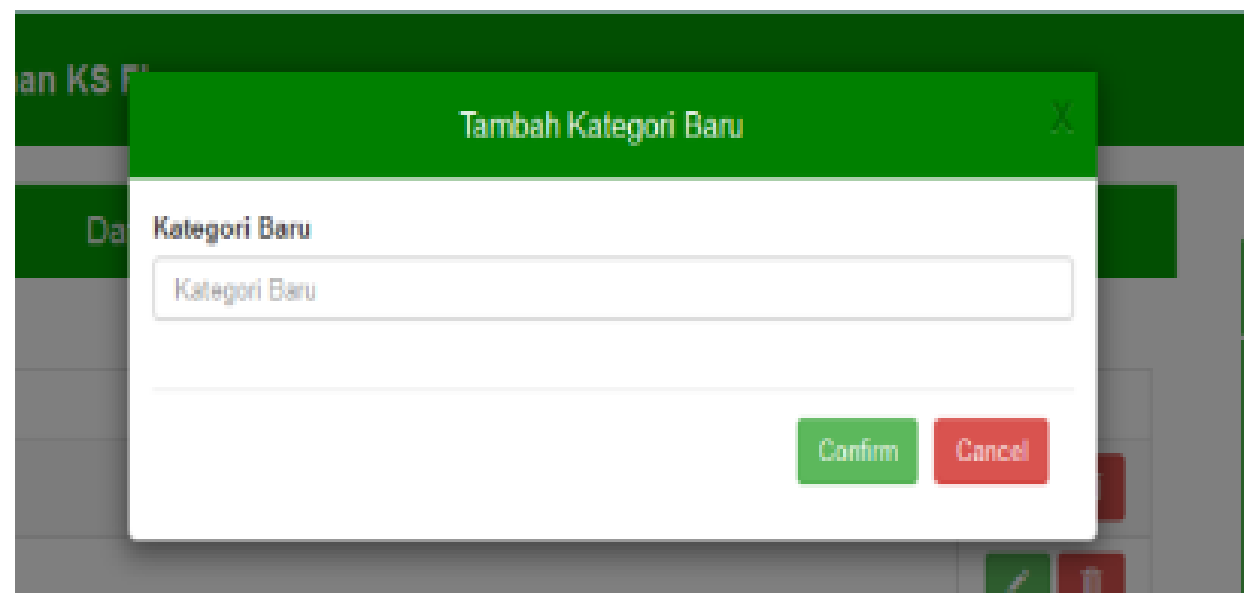

Gambar 7. Halaman Input Tambah Data Kategori 
Pada halaman ini untuk menampilkan data detail kategori. Tujuan adanya menu ini agar pelanggan bisa melihat detail tanamannya dulu baru dibeli. Untuk lebih jelas dapat dilihat pada Gambar 8.

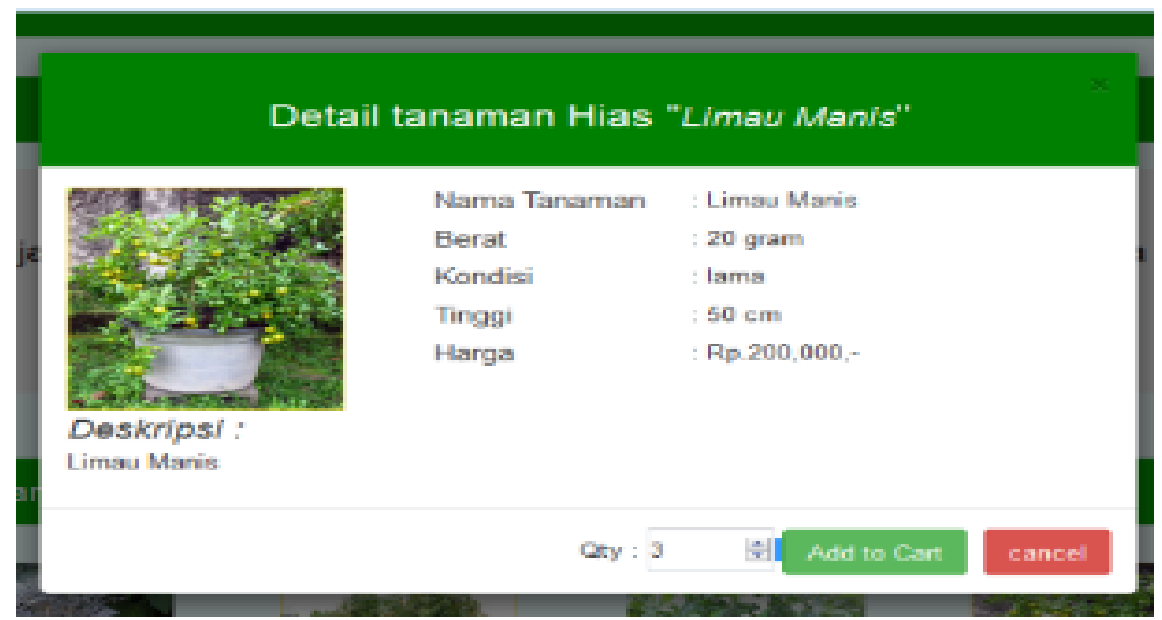

Gambar 8. Halaman Proses Pembelian Tanaman Hias

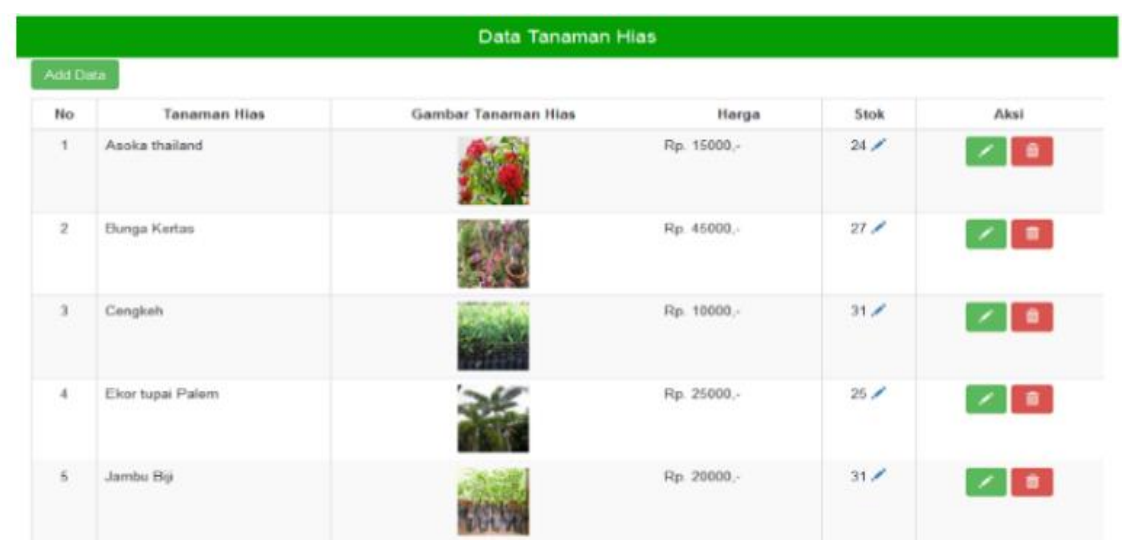

Gambar 9. Tampilan Halaman Data Tanaman Hias

Pada halaman ini merupakan halaman Menu Data Status Pengiriman. Halaman menu ini menampilkan daftar status pelanggan. Untuk lebih jelas dapat dilihat pada Gambar 10.

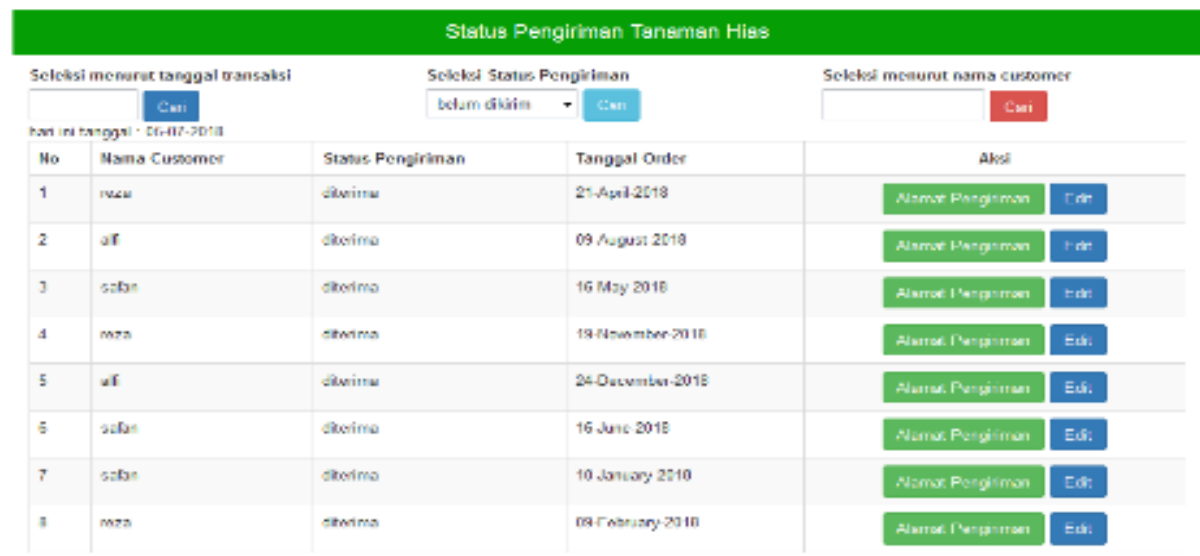

Gambar 10. Tampilan Halaman Status Pengiriman

Pada halaman ini dapat dilihat laporan Pemesanan tanaman hias selama setahun. Untuk lebih jelas dapat dilihat pada Gambar 11. 
SALMAN KS FLOWERS

JL ByPass KM 17 Simpang IV Lubuk Minturun Padang

HP: $081363730154-085263345144$

LAPORAI TRAISAKSI PEIIJUALAI

\begin{tabular}{|c|c|c|c|c|c|}
\hline NO. PEMESANAN & T ANGGAL ORDER & NAMA TANAMAN & HARGA & QTY & TOTAL BAYAR \\
\hline 13950 & $2018-0421$ & Kelengkeng & 380000 & 2 & 7899950 \\
\hline 14069 & $2018-08-09$ & Sugi India & 171000 & 9 & 485069 \\
\hline 17106 & $2018-05-16$ & Putri Salju & 130000 & 13 & 447106 \\
\hline 21152 & $2018-11-19$ & Mangga & 100000 & 5 & 3121152 \\
\hline 23371 & $2018-12-24$ & Putri Salyu & 140000 & 14 & 2963371 \\
\hline 26206 & $2018-06-16$ & Pucuk Ungu & 200000 & 2 & 3026206 \\
\hline 30516 & $2018-01-10$ & Piladang & 100000 & 2 & 2930516 \\
\hline 31135 & $2018-02-09$ & Piladang & 100000 & 2 & 3131135 \\
\hline 5974 & $2018-07-02$ & Limau Manis & 200000 & 1 & 505974 \\
\hline 7228 & $2018-08-15$ & Piladang & 200000 & 4 & 3007228 \\
\hline 7769 & $2018-00-01$ & Exortupai Palem & 150000 & 6 & 457769 \\
\hline
\end{tabular}

\begin{tabular}{|c|c|c|c|c|c|}
\hline 8901 & $2018-10-27$ & Bunga Kertas & 240000 & 12 & 3548901 \\
\hline \multicolumn{2}{|c|}{ SUBTOTAL } & 72 & 31518377 \\
\hline
\end{tabular}

Pimpinan

Gambar 11. Cetak Laporan Tahunan

Pada bagian analisa dari kelayakan sistem dilakukan dengan menggunakan pendekatan Metode System Usability Scale, metode ini adalah penggunaan data kuesioner dapat digunakan dalam mengukur usability suatu aplikasi yang berbasis komputer, menurut pandang satu sisi segi pemakai aplikasi [17]. Kemudian teknik ukuran SUS kuesioner dipakai adalah ukuran presepsi terdiri dari 5 nilai 1-5. Resonden diminta untuk memberikan skor "Sangat Setuju", "Setuju","Nertal","Kurang Setuju”, Sangat Kurang Setuju”. Adapun pertanyaan yang dinilai dapat dilihat pada Tabel 1 .

Tabel 1. Soal Analisa tentang aplikasi SUS yang diberikan kepada 30 Responden

\begin{tabular}{|l|l|}
\hline Kode & Item soal \\
\hline R1 & Apakah saya sering menggunakan sistem ini \\
\hline R2 & Saya melihat sistem ini sangat sederhana \\
\hline R3 & Saya melihat sistem ini mudah digunakan oleh pengguna \\
\hline R4 & Pada waktu menggunakan sistem saya tidak butuh bantuan \\
\hline R5 & Saya melihat manfaat sistem yang dirancang sudah sesuai \\
\hline R6 & Saya menilai sistem sudah menjalankan tugas dengan baik \\
\hline R7 & Saya menilai pengguna akan mudah menggunakan sistem \\
\hline R8 & Menurut saya sistem ini sangat sulit digunakan oleh pengguna \\
\hline R9 & Saya percaya diri menggunakan sistem ini \\
\hline R10 & Saya perlu belajar sebelum menggunakan sistem ini \\
\hline
\end{tabular}


Hasil dari kuesioner kemudian dihitung dengan menggunakan rumus yang telah ditentukan untuk mendapatkan nilai SUS pada Tabel 2.

Tabel 2. Hasil Perhitungan dengan nilai SUS

\begin{tabular}{|c|c|c|c|c|c|c|c|c|c|c|c|}
\hline Responden & R1 & R2 & R3 & R4 & R5 & R6 & R7 & R8 & R9 & R10 & $\begin{array}{l}\text { Skor } \\
\text { SUS }\end{array}$ \\
\hline 1 & 5 & 2 & 3 & 4 & 5 & 4 & 3 & 2 & 2 & 4 & 55 \\
\hline 2 & 4 & 3 & 5 & 3 & 4 & 3 & 4 & 5 & 2 & 5 & 50 \\
\hline 3 & 5 & 1 & 5 & 1 & 5 & 4 & 4 & 4 & 3 & 4 & 70 \\
\hline 4 & 4 & 4 & 4 & 4 & 4 & 4 & 5 & 4 & 4 & 4 & 53 \\
\hline 5 & 1 & 2 & 3 & 4 & 2 & 1 & 5 & 4 & 5 & 1 & 60 \\
\hline 6 & 5 & 2 & 5 & 2 & 4 & 2 & 4 & 2 & 4 & 1 & 83 \\
\hline 7 & 4 & 2 & 4 & 2 & 5 & 3 & 5 & 1 & 5 & 1 & 85 \\
\hline 8 & 4 & 2 & 5 & 1 & 5 & 1 & 5 & 1 & 5 & 2 & 93 \\
\hline 9 & 4 & 1 & 3 & 1 & 1 & 1 & 1 & 1 & 1 & 1 & 63 \\
\hline 10 & 5 & 1 & 3 & 2 & 2 & 4 & 4 & 4 & 2 & 4 & 53 \\
\hline 11 & 4 & 2 & 5 & 1 & 2 & 2 & 2 & 2 & 2 & 2 & 65 \\
\hline 12 & 3 & 2 & 2 & 1 & 5 & 1 & 5 & 1 & 4 & 1 & 83 \\
\hline 13 & 3 & 4 & 4 & 2 & 4 & 2 & 4 & 4 & 4 & 2 & 63 \\
\hline 14 & 5 & 3 & 5 & 2 & 4 & 1 & 4 & 2 & 5 & 2 & 83 \\
\hline 15 & 4 & 4 & 5 & 4 & 5 & 4 & 5 & 4 & 5 & 4 & 60 \\
\hline 16 & 5 & 2 & 4 & 1 & 5 & 2 & 5 & 2 & 5 & 1 & 90 \\
\hline 17 & 5 & 1 & 5 & 2 & 4 & 2 & 5 & 2 & 5 & 1 & 90 \\
\hline 18 & 5 & 2 & 5 & 1 & 4 & 5 & 1 & 1 & 4 & 1 & 73 \\
\hline 19 & 4 & 2 & 4 & 3 & 4 & 3 & 4 & 3 & 4 & 3 & 65 \\
\hline 20 & 5 & 1 & 3 & 1 & 4 & 1 & 4 & 5 & 4 & 1 & 78 \\
\hline 21 & 5 & 2 & 4 & 2 & 4 & 1 & 3 & 4 & 3 & 4 & 65 \\
\hline 22 & 4 & 2 & 5 & 3 & 4 & 5 & 5 & 5 & 3 & 5 & 53 \\
\hline 23 & 5 & 1 & 5 & 1 & 4 & 1 & 5 & 2 & 1 & 5 & 75 \\
\hline 24 & 5 & 1 & 4 & 2 & 5 & 2 & 5 & 1 & 5 & 2 & 90 \\
\hline 25 & 5 & 1 & 4 & 2 & 5 & 3 & 2 & 5 & 5 & 1 & 73 \\
\hline 26 & 4 & 2 & 4 & 4 & 4 & 4 & 5 & 4 & 5 & 2 & 65 \\
\hline 27 & 5 & 3 & 4 & 2 & 4 & 2 & 5 & 2 & 5 & 1 & 83 \\
\hline 28 & 5 & 2 & 5 & 1 & 3 & 4 & 2 & 4 & 5 & 1 & 70 \\
\hline 29 & 5 & 1 & 5 & 2 & 4 & 2 & 2 & 2 & 5 & 1 & 83 \\
\hline 30 & 5 & 1 & 5 & 2 & & 2 & 5 & 2 & 2 & 1 & 83 \\
\hline & \multicolumn{10}{|c|}{ Rata-Rata Skor SUS } & 72 \\
\hline
\end{tabular}

Hasil penilain dari skor SUS dapat dilihat pada tabel 2. Setelah dialakukan proses kemudian mendapatkan hasil dengan rata-rata Skor SUS sebesar $\mathbf{7 2}$ dengan tiga puluh responden. Kemudia hasilnya di cocokan dengan nilai kelas yang sudah ditentukan dalam metode penelitian [18], kelompok kelas di buat dalam enam seperti I, II, III, IV, V dan VI. 
Hasil uji dari sistem yang sudah dirancang dengan metode tersebut digolongkan kedalam kelas III, dimana kelas tersebut masuk dalam kelas bagus. Untuk lebih jelas dapat dilihat pada Gambar 12.

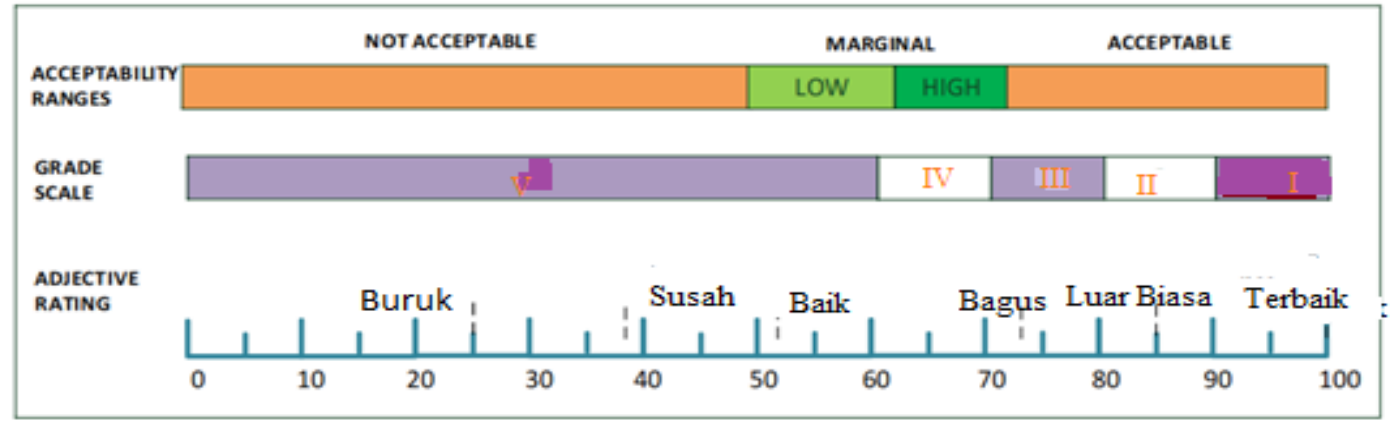

Gambar 12. Kelompok Dibuat Dalam Enam Kelas

Berdasarkan perhitungan pada tabel 2 dengan pengujian beta diberikan nilai oleh responen pada sistem yang sudah dibangun, diperoleh nilai dengan hasil layak dengan nilai rata-rata 72 . Responden terdiri dari 30 orang calon pengguna yaitu pelanggan salman KS Flowers. Hasil pengujian menunjukan $54 \%$ pengguna menilai aplikasi ini cukup layak digunakan, $30 \%$ menilai layak dan $16 \%$ menilai aplikasi ini kurang layak. Perhitungan yang dilakukan dapat disajikan dalam bentuk diagram seperti pada Gambar 13.

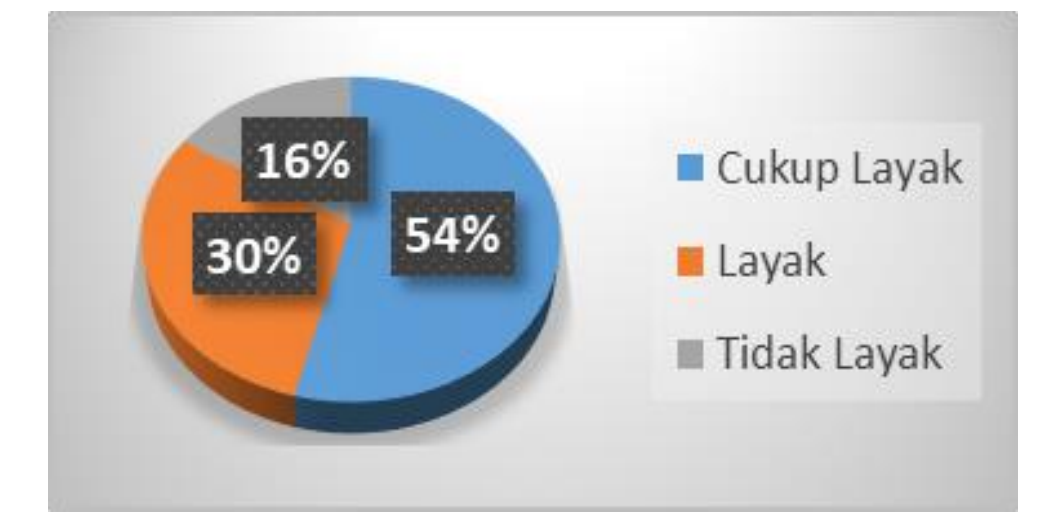

Gambar 13. Diagram Kelayakan Penilaian Aplikasi Oleh Pelanggan

\section{Kesimpulan}

Analisa dan perancangan Sistem yang perlu diperhatikan adalah kesesuaian perancangan interfrase dengan konten/isi yang ada dalam sistim interaaktif. Dalam perancangan juga sangat dipertatikan terhadap kode-kode dalam program sehingga aplikasi ini dapat berjalan dengan baik. Aplikasi ini dapat memberikan kemudahan bagi pihak manajmen slaman KS Flowers, admin, bagi karyawan dan juga bagi pelanggan dalam bertransaksi dalam proses pemesanan tanaman hias dimana pun pelanggan itu berada. Selain itu dengan adanya aplikasi ini pelanggan dapat mendapatkan informasi tentang informasi tanaman hias secara mudah dan cepat dibandingkan dengan cara convesional sebelum sistem ini dirancanga. Berdasarkan pengujian kelayakan dari sistem yang telah dilakukan oleh responden, sistem ini dinilai layak untuk digunakan dan didistribusikan dengan hasil pengujian sebesar 72 berdasrkan skala nilai SUS. Sedengkan untuk pengujian yang telah dilakukan sample user didapat $34 \%$ pengguna mengatakan aplikasi ini layak digunakan, 30\% cukup layak dan 16\% kurang layak.

Saran untuk penelitian berikutnya adalah dapat mengembangakan sistem yang lebih bagi lagi dan dapat disesuikan dengan perkembangan teknologi saat ini, seperti berbasis sakfor dan andoid, sehingga pelangan dapat lebih mudah lagi untuk mengakses aplikasinya. 


\section{Ucapan Terima Kasih}

Pengelitian ini dapat dilaksanakan dengan bantuan dari berbagai pihak, untuk itu diucapkan terima kasih yang tak terhingga kepada : Yayasan Amal Bakti Mukmin Padang, STMIK Indonesia Padang, Ketua LPPM STMIK Indonesia Padang dan Pimpinan CV. Salman Flowers. Penelitian ini merupakan hasil dari penelitian Hibah dosen STMIK Indonesia padang Nomor: /A12./STMIK-I/2018.

\section{Daftar Pustaka}

[1] L. Strategis, T. Pengembangan, and Z. A. Hasibuan, "Langkah-Lanngkah Strategis dan Taknis Pengembangan E-Goverment Untu Pemda," J. Sist. Inf. MTI UI Vol 3 - No. 1 April 2007, vol. 3, no. 1, pp. 1-5, 2007.

[2] S. Alliyah and R. Hidayat, "Peningkatan Kinerja UKM Dengan Mengimlementasikan Informasi Akuntansi Manajemen Yang Didukung Oleh Informasi Antar Unit," Staff Pengajar STIE “YPPI” Rembang 100, vol. 9, no. 2, pp. 100-111, 2014.

[3] A. Z. Adnan, "Penerapan Strategi Promosi Pada Pemasaran Produk CV. Syntax Corration Indonesia," Syntax Lit. J. Ilm. Indones. - ISSN 2541-0849 e-ISSN, vol. 3, no. 7, pp. 14-24, 2018.

[4] N. Baladina, R. Anindita, and B. Setiawan, "Penguatan ketahanan pangan nasional melalui strategi perbaikan efisiensi pemasaran hasil pertanian," SEPA, vol. 11, no. 1, pp. 55-65, 2014.

[5] V. M. M. Siregar, "Perancangan Website Sebagai Media Promosi Dan Penjualan Produk," J. TAM (Technology Accept. Model., vol. 9, pp. 15-21, 2018.

[6] D. S. Adi and R. Pandalu, "Efektivitas Pelayanan Informasi Internal Kampus Melalui Pemanfaatan Media Interaktif Berbasis Artom ( Studi Fenomenologi Pada Mahasiswa FISIP Universitas Merdeka Malang ), September, pp. 91-100, 2017.

[7] A. R. N. Ajeng Jayanti Satyadewi, Hanny Hafiar, "Pemilihan Akun Media Sosial Instagram Oleh Holidy Inn Bandung," J. MESSENGER, vol. 9, no. April, pp. 153-162, 2017.

[8] L. M. Rini Asmara1, Imam Gunawan2, "Pengolahan Data Gaji Hoorer Dan Perjalanan Dinas Pegawai THL Berdasarkan Surat Perintah Tugas," J. J-CLICK, vol. 5, no. 1, pp. 72-84, 2018.

[9] V. Motumona, U. Lestari, E. Fatkhiyah, and P. T. Informatika, "Sistem Informasi Geografis Lokasi Perguruan Tinggi Di Daerah Istimewa Yogyakarta Berbasis Moblle Android Jurnal SCRIPT Vol . 4 No . 1 Desember 2016 ISSN : 2338-6313," J. Scr., vol. 4, no. 1, pp. 72-78, 2016.

[10] dan A. P. Fatkhul Amin, R. Soelistijadi, "Aplikasi E-Commerce Sentra Batik di Kota Semarang Sebagai Salah Satu Upaya Media Promosi dan Transaksi Secara Online," J. Teknol. Inf. Din., vol. 17, no. 1, pp. 67-74, 2012.

[11] R. A. R. Resty Wulanningrum1, Risa Helilintar2, "Penerapan Aplikasi E-Business Sebagai Salah Satu Usaha Peningkatan Penjualan Tanaman," J. ABDINUS http//ojs.unpkediri.ac.id/index.php/PPM, vol. 1, no. 1, pp. 69-74, 2017.

[12] S. A. Pratiwi, I. M. Sukarsa, I. K. A. Purnawan, J. T. Informasi, F. Teknik, and U. Udayana, "Rancang Bangun Aplikasi Sistem Pemesanan Bunga Berbasis Android," MERPATI, vol. 2, no. 2, pp. 205-214, 2014.

[13] R. S. Umi Salamah1), Wiharto2), "Pembangunan E-Commerce Untuk Usaha Mikro Kecil Dann Menengah ( Studi Kasus Sentra UMKM Dian Nurcery dan Mawar Indah , Tawangmangu ) JOGLO , Volume XXVII No . 2 - Pebruari 2015 JOGLO , Volume XXVII No . 2 - Pebruari 2015," JOGLO, vol. XXVII, no. 2, pp. 285-289, 2015.

[14] 1)Wildy Y. P. Taroreh, "Sistem Informsi Penjualan Bunga Berbasi Web," Bul. Sariputra, vol. 4, no. 3, pp. 259-264, 2014. 
[15] V. Herlianti and K. Karpen, "Aplikasi Pemasaran Otak-Otak Kering Menggunakan Strategi Marketing Mix Berbasis Android," Digit. Zo. J. Teknol. Inf. dan Komun., vol. 9, no. 2, pp. 182-193, 2018.

[16] M. A. M. Roni Kurniawan1, Jeffry Nur Rifa'i2, "Analisis dan Perancangan Sistem Informasi Penerbitan Surat di PDAM Tirta Moedal Kota Semarang Cabang Timur," Techno.COM, Vol. 17, No. 2, Mei 2018 145-157 ISSN, vol. 17, no. 2, pp. 145-157, 2018.

[17] I. A. H. N, P. I. Santoso, and R. Ferdiana, "Pengujian Usability Website Menggunakan System Usability Scale Website Usability Testing using System Usability Scale," IPTEK-KOM, VOL.17 NO.1, vol. 17, no. 1, pp. 31-38, 2015.

[18] U. Ependi and F. Panjaitan, "System Usability Scale Antarmuka Palembang Guide Sebagai Media Pendukung Asian Games XVIII," J. Inf. Syst. Eng. Bus. Intell. Vol. 3, No. 2, vol. 3, no. 2, 2018.

\section{(c) (i) (2)}

Digital Zone: Jurnal teknologi informasi dan Komunikasi is licensed under a Creative Commons Attribution International (CC BY-SA 4.0) 